\title{
E o seu Nome é Jonas: Recursos Visuais e Textuais/Verbais como Crítica ao Discurso Oralista na Educação de Surdos
}

\author{
And his Name is Jonas: Visual and Textual / Verbal \\ Resources as a Criticism to Oralist Speech in Deaf \\ Education
}

\section{Y su Nombre es Jonas: Recursos Visuales y Textuales / Verbales como Crítica del Discurso Oralista en la Educa- ción Sorda}

\author{
(iD) Tatiane da Silva Carvalho Pereira \\ Universidade Estadual de Goiás \\ iD Gláucia Vieira Cândido \\ Universidade Estadual de Goiás \\ iD (9) Jorge Lucas Marcelo dos Santos \\ Universidade Estadual de Goiás
}

Resumo: Este artigo propõe uma análise crítica discursiva dos recursos visuais e textuais/verbais usados em E o seu nome é Jonas, filme dirigido por Richard Dick Michaels (1979), cujo conteúdo aborda a filosofia oralista. À luz da Análise do Discurso Crítica (FAIRCLOUGH, 2001; ALMEIDA, 2008), objetivamos identificar e analisar a prática discursiva presente no longa-metragem. Para tanto, o texto aborda demarcações teóricas e metodológicas referentes ao processo educativo da pessoa surda e discute o contexto histórico das filosofias educacionais, conforme Goldfeld (2002) e Quadros (1997). 
Os resultados apontam para a desconstrução da filosofia oralista, amplamente defendida no final da década de 1980, no Congresso de Milão. Atestam, ainda, em consonância com Christmann (2015), Pereira (2020), dentre outros pesquisadores, que a falta de acesso do surdo às informações é provocada pela ausência de comunicação, a qual, indubitavelmente, pode ser feita por meio da língua de sinais. Além disso, essa análise ressalta a função linguística que a língua de sinais exerce na vida dos surdos, mesmo convivendo em ambientes majoritariamente compostos por pessoas ouvintes. Ou seja, quanto mais cedo a língua de sinais for inserida no seio familiar e no ambiente de educação formal da criança surda, mais êxito se verificará no desenvolvimento social e cognitivo do sujeito surdo. Palavras-chave: Educação de surdos. Filosofia oralista. Língua de sinais.

2

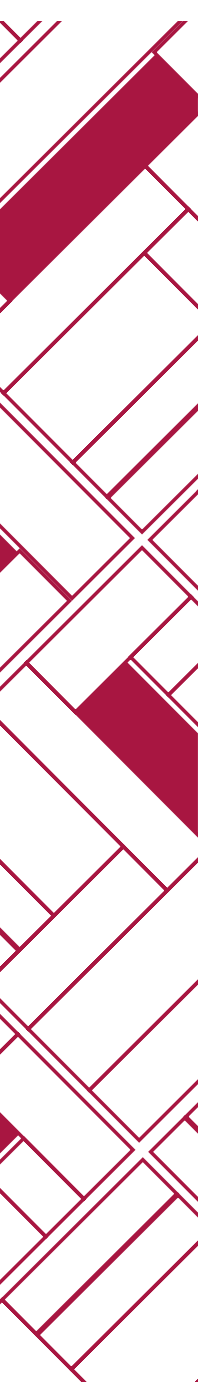

Abstract: This article proposes a critical discursive analysis of the visual and textual / verbal resources used in And his name is Jonas (1979), a film directed by Richard Dick Michaels, whose content addresses oralist philosophy. In the light of Critical Discourse Analysis (FAIRCLOUGH, 2001; ALMEIDA, 2008), we seek to identify and analyze the discursive practice present in the feature film. To this end, the text addresses theoretical and methodological demarcations on the educational process of the deaf person and discusses the historical context of educational philosophies, according to Goldfeld (2002) and Quadros (1997). The results point to the deconstruction of oralist philosophy, widely defended in the late 1980s, at the Milan Congress. They also attest, in line with Christmann (2015), Pereira (2020), among other researchers, that the lack of access by deaf to information is caused by a lack of communication, which can undoubtedly be done through sign language. In addition, this analysis highlights the linguistic function that sign language plays in the lives of the deaf, even living in environments 
composed mainly of people who listen. That is, the sooner the sign language is inserted in the family and in the formal education environment of the deaf child, the more success will be verified in the social and cognitive development of this deaf subject.

Key words: Deaf education. Oralist philosophy. Sign language.

Resumen: Este artículo propone un análisis discursivo crítico de los recursos visuales y textuales / verbales utilizados en $Y$ su nombre es Jonas (1979), una película dirigida por Richard Dick Michaels, cuyo contenido aborda la filosofía oralista. A la luz del Análisis Crítico del Discurso (FAIRCLOUGH, 2001; ALMEIDA, 2008), buscamos identificar y analizar la práctica discursiva presente en el largometraje. Con este fin, el texto aborda las demarcaciones teóricas y metodológicas sobre el proceso educativo de la persona sorda y discute el contexto histórico de las filosofías educativas, según Goldfeld (2002) y Quadros (1997). Los resultados apuntan a la deconstrucción de la filosofía oralista, ampliamente defendida a fines de la década de 1980, en el Congreso de Milán. También atestiguan, en línea con Christmann (2015), Pereira (2020), entre otros investigadores, que la falta de acceso por parte de sordo a la información es causado por una falta de comunicación, que sin duda se puede hacer a través del lenguaje de señas. Además, este análisis destaca la función lingüística que desempeña el lenguaje de señas en la vida de los sordos, incluso viviendo en entornos compuestos principalmente por personas que escuchan. Es decir, cuanto antes se inserte el lenguaje de señas en la familia y en el entorno educativo formal del niño sordo, más éxito se verificará en el desarrollo social y cognitivo de este sujeto sordo.

Palabras-clave: Educación de sordos. Filosofía oralista. Lenguaje de señas.

Data de submissão: 17/08/2020

Data de aprovação: 10/10/2020 
E o Seu Nome é Jonas: Recursos Visuais e Textuais/Verbais como Crítica ao Discurso Oralista na Educação de Surdos

Tatiane da Silva Carvalho Pereira • Gláucia Vieira Cândido, et al...

\section{Introdução}

A história tem mostrado que nem sempre as práticas discursivas construídas e difundidas acerca das pessoas surdas foram consideradas positivas. Afinal, desde a antiguidade, materialidades linguísticas, socioculturais, históricas, literárias e ideológicas têm nos feito compreender que os surdos, de modo geral, protagonizaram discursos nos quais eram percebidos a partir de um olhar de piedade e compaixão, por serem considerados, nas palavras de Goldfeld (2002, p. 27), pessoas "castigadas pelos deuses ou enfeitiçadas, o que decorria em abandonos ou mesmo sacrifícios".

Esse panorama persistiu até poucas décadas. No Brasil, por exemplo, Silva relatou, detalhadamente, como seus dois irmãos surdos eram vistos na infância. Segundo a autora, era comum as pessoas, e até a própria família, se referirem a seus irmãos como "deficientes", "coitadinhos" ou "doentes". Ao contrário disso, para Silva (2013, p. 13), "o convívio com os dois era a garantia de brincadeiras, bagunças e até brigas de irmãos". Enfim, como era de se esperar, existia entre os três um relacionamento fraterno e dentro da normalidade possível, haja vista a dificuldade de comunicação imposta pelo fato de a mãe das crianças não permitir à garota que gesticulasse para os irmãos surdos.

Assim, Silva (2013) relata que a genitora acabava por reproduzir a fala da escola, onde os irmãos estudavam e cuja prática de ensino estava focada na estimulação oral e auditiva das crianças surdas. De acordo com a autora, a mãe acreditava que, se os filhos aprendessem a fazer sinais, poderiam sentir preguiça de oralizar, o que não poderia ocorrer. Dessa maneira, a família não conheceu a língua de sinais enquanto os três irmãos eram crianças e adolescentes.

Parte desse contexto real, e de vários outros mundo afora, é retratado na obra cinematográfica $E$ o seu nome é Jonas, filme diri- 
E o Seu Nome é Jonas: Recursos Visuais e Textuais/Verbais como Crítica ao Discurso Oralista na Educação de Surdos

Tatiane da Silva Carvalho Pereira • Gláucia Vieira Cândido, et al...

gido por Richard Dick Michaels (1979). Esse filme narra a história do pequeno Jonas Corelli, um garoto surdo, que fora internado em um hospital psiquiátrico durante três anos, devido a um equivocado diagnóstico de deficiência mental. Ao perceberem o erro médico, seus pais o retiram da instituição, levando-o de volta para casa, onde encontrou seu irmão, Antônio.

Na sequência, o protagonista passou a utilizar um aparelho auditivo. Por isso, sua mãe, Jenny Corelli, decidiu matriculá-lo em uma instituição de ensino que utilizava apenas métodos oralistas. Contudo, nessa nova escola, o garoto não conseguia acompanhar a turma pelo fato de não ser permitido o uso de sinais na sala de aula.

Para os educadores dessa escola, o uso dos sinais poderia estimular a não oralização do aluno surdo e, consequentemente, isso o levaria a querer se comunicar somente com colegas que também fossem surdos. No discurso da diretora, sublinhamos as seguintes palavras: "Infelizmente, o mundo é dos ouvintes!"”.

A partir desse contexto, logo no início do filme, deparamo-nos com um ambiente escolar desafiador, pois a tarefa de aprender a ler lábios e a falar mostrou-se extremamente difícil e frustrante para Jonas. Esse jovem, por sua surdez, não conseguia perceber 0 "sentido" do processo de ensino e aprendizagem da pronúncia das palavras cujos sons não eram ouvidos por ele.

Além disso, o filme revela que as dificuldades de Jonas na escola deixavam sua mãe muito apreensiva e nervosa. O convívio familiar tornou-se tumultuado, pois o pai de Jonas, Danny Corelli, enfrentou muitas dificuldades para lidar com a situação, ao ponto de sugerir a reinternação de Jonas no hospital psiquiátrico, visando o retorno da "paz" ao lar. Todavia, a recusa da Sr. a Jenny Corelli à sugestão do Sr. Corelli culminou no abandono da família por este homem que era marido e pai.

1 - Segundo a perspectiva bakhtiniana de linguagem, o signo linguístico é necessariamente ideológico, pois carrega em si os conflitos das forças sociais que os operam. Tais forças se consolidam relativamente nos parâmetros sociais e econômicos de uma época. É o que esse discurso da diretora revela sobre uma narrativa que se passa na década de 1960. 
E o Seu Nome é Jonas: Recursos Visuais e Textuais/Verbais como Crítica ao Discurso Oralista na Educação de Surdos

Tatiane da Silva Carvalho Pereira • Gláucia Vieira Cândido, et al...

Como mostra o filme, a Sr. ${ }^{a}$ Corelli, após sua separação, conheceu uma família de surdos que se comunicava por meio de sinais. Era, enfim, a porta de entrada para o universo dos surdos de que tanto necessitavam filho e mãe. Por causa da interação com essa família, Jonas e a Sr. ${ }^{a}$ Corelli começaram a entender o funcionamento da língua de sinais e a aprender mais sobre a cultura surda.

Na referida dramaturgia, observamos que se destaca o sentimento de angústia tanto do protagonista Jonas quanto de sua mãe, pois essas duas personagens não conseguem estabelecer boa comunicação e compreensão mútua. A Sr. ${ }^{a}$ Corelli, por exemplo, não conseguiu identificar e propor soluções aos problemas vividos por Jonas na escola. Daí, a angústia se tornou mais um elo entre os dois.

No desenrolar do enredo fílmico, algumas cenas e diálogos, a nosso ver, estabelecem uma conexão com a tentativa de construção ideológica em torno da cultura "ouvintista", que é fortemente atribuída ao personagem Jonas em suas relações sociais e afetivas. Nesse sentido, ressaltamos que a época em que o filme foi produzido fora marcada por um histórico de lutas de pessoas surdas pelo direito de uso das línguas de sinais.

No âmbito dessas considerações, apresentamos uma breve análise dos recursos visuais e textuais/verbais que envolvem o drama encenado no filme de Michaels (1979). Especificamente, importa-nos explicitar as relações de poder existentes na narrativa fílmica, visto que algumas marcas discursivas presentes nos levaram a identificar a tentativa de construir uma representação contrária à que estava sendo estabelecida pela narrativa, ou seja: a filosofia bilinguista em detrimento da oralista.

Para tanto, buscamos em Fairclough (2001) pressupostos teóricos que nos permitem compreender as relações de sentido construídas pelo funcionamento da língua(gem) em sociedade. 
E o Seu Nome é Jonas: Recursos Visuais e Textuais/Verbais como Crítica ao Discurso Oralista na Educação de Surdos

Tatiane da Silva Carvalho Pereira • Gláucia Vieira Cândido, et al...

Nessa perspectiva, o objeto de análise deste artigo pode ser compreendido como manifestação de linguagem (cinematográfica), pois imprimi ao texto (o filme) o caráter de discurso. Sobre isso, Fairclough (2001) acrescenta que, por meio do discurso, não apenas é possível representar o mundo, como, para muito além disso, é possível (re)significá-lo.

No panorama geral da ADC, os elementos linguísticos de uma materialidade significante, como a produção audiovisual de Michaels (1979), devem ser considerados a partir de suas implicações discursivas, uma vez que esse entendimento corrobora o que Fairclough (2001) entende por "discurso". Para ele, o discurso é entendido como ação e representação sob a forma de linguagem (texto), uma vez que "os eventos discursivos específicos variam em sua determinação estrutural segundo o domínio social particular ou o quadro institucional em que são gerados" (FAIRCLOUGH, 2001, p. 91).

Nesse sentido, acreditamos que a análise do discurso crítica auxiliará no estudo dos processos de produção do texto e do discurso, bem como na observação de como os recursos visuais e textuais/verbais são utilizados e articulados para além no nível da textualidade. Portanto, nosso objetivo é compreender, a partir da $A D C$, as relações de poder que apontam para os sentidos obtusos propagados pelo discurso. Para tanto, tomamos como objeto de análise o filme de Michaels (1979).

Do ponto de vista metodológico, empregamos a pesquisa bibliográfica com abordagem qualitativa, cujas características possibilitam aos pesquisadores explorarem aspectos subjetivos do que está sendo pesquisado. Além disso, a análise bibliográfica é responsável por apresentar conceitos e instrumentos de análise dos recursos visuais e textuais/verbais que contrastam com a proposta de tentativa de desconstrução da filosofia oralista em favor da proposta bilíngue. 
E o Seu Nome é Jonas: Recursos Visuais e Textuais/Verbais como Crítica ao Discurso Oralista na Educação de Surdos

Tatiane da Silva Carvalho Pereira • Gláucia Vieira Cândido, et al...

A partir disso, o percurso metodológico empregado foi dividido em quatro etapas: 1. delimitar o escopo de observação por meio da captura de imagens do garoto Jonas em quatro momentos distintos, sendo eles: a) Jonas colocando o boneco do Homem Aranha na gaveta diante da placa de stop (Imagem - 1); b) Jonas colocando o boneco do Homem Aranha embaixo de um móvel diante da placa de stop ( Imagem - 2); c) O boneco do Homem Aranha sendo carbonizado (Imagem - 3); d) Jonas conversando em língua de sinais com a mãe (Imagem - 4); 3. selecionar bibliografia referente à temática estudada e ao corpus escolhido; 4. identificar, compreender e analisar os símbolos, as imagens e os recursos visuais e textuais/verbais que apontam para os objetivos propostos; e, por fim, 5. redigir o texto do artigo e suas conclusões.

\section{Os processos educativos da pessoa surda}

Segundo Honora (2014, p. 51), no âmbito da filosofia grega, Aristóteles defendia que a audição era o sentido mais importante para o sucesso da escolarização. Baseando-se nesse pensamento, a sociedade impedia que os surdos recebessem instruções educacionais. A autora afirma também que, na idade média, sob forte influência da Igreja Católica e preceitos de que o homem fora criado a partir da "imagem e semelhança de Deus", as pessoas que não se encaixavam nesse padrão de “normalidade" não eram consideradas humanas. Nesse campo ideológico, os surdos não eram aceitos pela família tampouco pela sociedade. Dessa maneira, acabavam tendo que viver à margem dela, sendo proibidos de frequentar as reuniões familiares ou outros espaços sociais da época.

Naturalmente, essa construção negativista da pessoa surda teve profundo impacto na vida de indivíduos surdos por longo período. Isso foi determinante para que permanecesse a ideia de que eles não poderiam ser educados nos moldes da educação formal. Essa realidade se 
E o Seu Nome é Jonas: Recursos Visuais e Textuais/Verbais como Crítica ao

Discurso Oralista na Educação de Surdos

Tatiane da Silva Carvalho Pereira • Gláucia Vieira Cândido, et al...

perpetuou da antiguidade até o século XV, quando os surdos estiveram totalmente excluídos da sociedade.

A história que envolve o processo educacional e o reconhecimento da pessoa surda como ser humano, e como sujeito passível de aprendizagem, começou a ser (re)configurada quando Ponce de Leon (15201584) passou a ensinar alguns surdos, ou melhor, filhos de nobres que apresentavam a surdez. Sua metodologia envolvia a datilologia², a escrita e a oralização para o ensino de línguas estrangeiras, além de conceitos físicos e matemáticos.

De acordo com Goldfeld (2002), outro importante personagem na trajetória de educação das pessoas surdas foi o Abade Charles Michel de L'Epée, que se dedicou à causa aproximando-se dos surdos que moravam nas ruas de Paris e aprendendo com eles os "sinais metódicos", que são uma combinação da língua de sinais com a gramática sinalizada francesa.

A partir dessas contribuições, sublinhamos que o século XVIII é considerado o período mais fértil da educação de surdos, pois houve um grande impulso de escolas para surdos, no sentido quantitativo. Do ponto de vista qualitativo, também houve avanços, tendo em vista que se percebeu que, por meio da língua de sinais, os surdos podiam aprender e dominar diversos assuntos e exercer várias profissões.

Todavia, no século XIX, em razão dos avanços tecnológicos, um processo de facilitação da aprendizagem do surdo pela fala ocorreu. Daí, especificamente, a partir da década de 1860, o método oral passou a ganhar força (GOLDFELD, 2002). Concomitantemente, muitos profissionais começaram a investir no aprendizado da língua oral pelos surdos, o que deu origem à ideia de que a língua de sinais seria prejudicial para a aprendizagem da língua oral. Essa colocação foi fortalecida e defendida até os dias atuais. É nesse contexto, portanto, que começaram a surgir ideias contrárias ao uso da língua de sinais.

2 - No repertório linguístico dos sinalizantes de Libras, 'datilologia' é o procedimento usado para soletrar nomes próprios de pessoas ou lugares, siglas, acrônimos, palavras inexistentes em sinais ou mesmo para realizar sinais de pontuação (vírgula, ponto final, interrogação etc.), recorrendo aos devidos empréstimos da grafia da língua oral, por exemplo (GESSER, 2012, p. 146). Para Kojima e Segala (2008, p. 9), a Datilologia é a arte de conversar configurando as mãos. A forma que a mão assume de uma letra está indicada no alfabeto manual, ou seja, uma série de letras convencionais que correspondem às letras escritas. 
E o Seu Nome é Jonas: Recursos Visuais e Textuais/Verbais como Crítica ao Discurso Oralista na Educação de Surdos

Tatiane da Silva Carvalho Pereira • Gláucia Vieira Cândido, et al...

Alexander Grahan Bell (1880), notável inventor do aparelho de telefone, foi também um poderoso e influente defensor do oralismo e do "ouvintismo", termo que, conforme Skliar (2016, p. 15), designa um conjunto de representações dos ouvintes, a partir do qual o surdo fica obrigado a se ver como um ouvinte. Isto é, segundo essa filosofia, o surdo é orientado a colocar-se no lugar de quem ouve dentro da normalidade. Ou seja, é nesse "olhar-se" e "narrar-se" que acontecem as práticas terapêuticas habituais.

Por isso, em 1880, no Congresso Internacional de Educadores de Surdos, realizado em Milão, o célebre Alexander Grahan Bell exerceu papel decisivo na votação do método que deveria ser utilizado na educação de surdos. Com a vitória do Oralismo, o uso da língua de sinais foi oficialmente proibido. Tudo isso aconteceu sem a participação dos professores surdos, aos quais foi negado o direito de votar.

Disso, depreendemos que a concepção de linguagem, para os profissionais seguidores da "filosofia oralista", restringia-se à modalidade oral da língua, já que esta deveria ser, então, a única forma de comunicação entre os surdos. Nesse cenário, com a oralização, os surdos passaram a maior parte do tempo fazendo exercícios por meio de fonoterapia, no sentido de que pudessem dominar a língua oral. Daí, a proposta de ensino por disciplinas, como matemática, história e geografia, ser relegada, ou seja, ficando em segundo plano. Além disso, a partir dessas ideias, houve declínio significativo no nível de escolarização dos alunos surdos (GOLDFELD, 2002, p. 31).

Em relação ao fato de que era possível observar potencialmente o desenvolvimento dos alunos surdos a partir das metodologias aplicadas por meio das línguas de sinais, verificamos que, após o Congresso de Milão, ocorre rápida implantação dos métodos oralistas. Sobre isso, Campos (2014) ressalta que:

apesar dos bons resultados, em 1880, no Congresso de Milão, fórum de debate mundial sobre a educação de surdos, foi 
E o Seu Nome é Jonas: Recursos Visuais e Textuais/Verbais como Crítica ao Discurso Oralista na Educação de Surdos

Tatiane da Silva Carvalho Pereira • Gláucia Vieira Cândido, et al...

aprovada a filosofia do oralismo, tendo por objetivo a proibição da língua de sinais e imposição da língua oral. A oralização, um método difundido por Alexander Bell, veio encapsular os surdos no modelo do ouvintismo, ou seja, de acordo com as regras da "normalidade". Este fato provocou uma revolta entre os surdos, pois a proibição de sua própria língua prejudicaria suas identidades, cultura e educação. Foi observado que os surdos não apresentavam progressos no desenvolvimento linguístico, cognitivo, afetivo e de linguagem por meio desse método (CAMPOS, 2014, p. 39).

A proibição do uso da língua de sinais foi, para os surdos, um grande regresso. Uma vez tolhido o uso da língua de sinais, além do possível insucesso da oralização, consequentemente, suas capacidades cognitivas e intelectuais acabavam sendo comprometidas também. Segundo Honora (2014, p. 57), a proibição do uso dos sinais levou cem anos para ser contestada, o que causou retrocesso na educação dos surdos, pois, após oito ou dez anos de escolarização, os surdos, em sua maioria, se tornavam sapateiros ou costureiros e, para piorar, não adquiriam a oralização e acabavam sendo considerados, pejorativamente, como "retardados".

A hegemonia da filosofia oralista no mundo durou, como já dito, quase um século. De acordo com Goldfeld (2002), isso ocorreu até a década de 1970, quando William Stokoe publicou o artigo Sign Language Structure: An Outline of the Visual Communication System of the American Deaf, com o objetivo de defender a American Sign Language (ASL), sendo esta uma língua com todas as características das línguas orais. Após essa publicação, diversas outras pesquisas sobre as línguas de sinais referentes à sua aplicação na educação e na vida das pessoas surdas foram divulgadas.

De acordo com Harrison (2014, p. 31), a pesquisa de Stokoe pode ser considerada o texto fundamental dos estudos linguísticos das línguas de sinais. Esse estudo viabilizou outras pesquisas, ou melhor, ou- 
E o Seu Nome é Jonas: Recursos Visuais e Textuais/Verbais como Crítica ao Discurso Oralista na Educação de Surdos

Tatiane da Silva Carvalho Pereira • Gláucia Vieira Cândido, et al...

tros pesquisadores começaram a seguir tais ideias, trazendo contribuições para os seus achados científicos, estendendo sua tese para todo o mundo.

Segundo Goldfeld (2002, p. 31), como a maioria desses estudos estava aliada a uma enorme insatisfação com método oral, tanto por parte dos surdos quando dos educadores, originou-se um movimento pela utilização da língua de sinais e de outros códigos manuais na educação da criança surda.

A partir desse cenário, portanto, entendemos que, para aqueles que defendem a concepção oralista, a surdez é percebida como uma deficiência, sendo esta minimizada pela estimulação auditiva, que, por sua vez, possibilitaria a aprendizagem, em nosso contexto, por exemplo, da língua portuguesa. Além disso, levaria a criança surda a integrar-se na comunidade ouvinte. Por consequência, a pessoal surda acabaria desenvolvendo uma personalidade semelhante à de um ouvinte. Em síntese, como ressalta Goldfeld (2002, p. 33), o objetivo educacional da filosofia oralista é fazer uma reabilitação da criança surda em direção à normalidade, ou melhor, à "não surdez".

Campos (2014), por sua vez, corrobora essa reflexão ao asseverar que a oralização encapsulou os surdos no modelo do ouvintismo, ou seja, segundo as regras do que é considerado "normal". Para a autora, esse episódio provocou descontentamento entre a comunidade surda, uma vez que a proibição de sua própria língua, a sinalizada, prejudicaria a identidade da pessoa surda, bem como sua cultura e educação. Afinal, havia evidências de que os surdos não estavam progredindo em seu desenvolvimento linguístico, cognitivo, afetivo e de linguagem, por meio desse método.

Diante desse contexto, estruturado pelos resultados negativos advindos da proposta oralista, surge a abordagem da Comunicação Total. De acordo com Goldfeld, em 1968, Roy Holcom adotou o Total Approach, rebatizando-o de Total Comunication, dando origem à filosofia da Comunicação Total. Segundo a autora, essa abordagem era utilizada na educação de surdos, além de facilitar a comunicação entre eles, justamente 
E o Seu Nome é Jonas: Recursos Visuais e Textuais/Verbais como Crítica ao

Discurso Oralista na Educação de Surdos

Tatiane da Silva Carvalho Pereira • Gláucia Vieira Cândido, et al...

por acreditar que a comunicação - e não a língua - deveria ser privilegiada (GOLDFELD, 2002, p. 32).

Portanto, a prática oralista passou a refletir negativamente nos processos de ensino e aprendizagem. Além disso, devido à constatação de fracassos educacionais, os movimentos surdos passaram a vislumbrar a possibilidade de reconquistar, efetivamente, o direito ao uso da língua de sinais nas práticas de ensino. Isso culminou no surgimento da filosofia Bilíngue. Dessa forma, em meados da década de 1970, o surgimento de pesquisas relacionadas à comprovação da estrutura das línguas de sinais, aliado ao descontentamento das pessoas surdas acerca do método oralista, fortaleceu a filosofia do Bilinguismo, que, na década de 1990, ganhou mais adeptos em todo o mundo (GOLDFELD, 2002, p. 32).

Assim, na década de 1980, o Bilinguismo começa a emergir no Brasil com base nas pesquisas da professora Lucinda Ferreira Brito sobre a língua de sinais brasileira. A Língua de Sinais dos Centros Urbanos Brasileiros, conforme Goldfeld (2002, p. 33), seguindo um padrão internacional de abreviação das línguas de sinais, foi abreviada pela pesquisadora de LSCB. Contudo, a partir de 1995, Brito passou a utilizar a nomenclatura Língua Brasileira de Sinais (Libras), conforme retificado por Pereira (2020).

Sob outra perspectiva, o Bilinguismo tem como pressuposto básico que o surdo deve ser bilíngue, ou seja, que uma criança surda deve adquirir a língua de sinais como sua língua materna, haja vista ser considerada a língua natural dos surdos; e, como segunda língua, aquela que está na posição de língua oficial de seu país, no Brasil, majoritariamente, o Português³.

Em relação à efetivação estrutural da proposta bilíngue, Quadros (1997, p. 27) assevera que o Bilinguismo é um projeto educacional usado nas escolas com o objetivo de tornar acessível à criança surda as duas línguas (oral escrita e a de sinais) no contexto escolar. Além disso, a língua de sinais é considerada como a língua natural da criança surda.

3 - Importante salientar que o Brasil é um país multilíngue e pluricultural. Diversas línguas indígenas são faladas no Brasil e, nestes casos, sendo elas oficiais ou não, são o caso de primeiras línguas para crianças surdas indígenas. 
E o Seu Nome é Jonas: Recursos Visuais e Textuais/Verbais como Crítica ao Discurso Oralista na Educação de Surdos

Tatiane da Silva Carvalho Pereira • Gláucia Vieira Cândido, et al...

Grosjean (2001 apud SILVA, 2015), ao discutir o direito do surdo de ser bilíngue, aponta as competências que a criança, nessa condição, deve desenvolver como bilíngue. O autor defende que toda criança surda deve crescer usando tanto a língua de sinais quanto a língua oral escrita e, se não houver impedimento, em sua modalidade falada também. Se a família colocar em prática esse direito, garantirá à criança o desenvolvimento de suas capacidades cognitivas, linguísticas e sociais.

Pautados nessa breve abordagem do contexto histórico referente às línguas de sinais, passaremos à proposta de análise do filme de Michaels (1979), com vistas a identificar tentativas de desconstrução da filosofia oralista e a defesa da filosofia bilíngue. Para tanto, apoiar-nos-emos em Thompson (1995) e Kress e van Leeuwen (2000 apud ALMEIDA, 2008).

Na concepção de Thompson (1995, p. 96), 'ideologia' é concebida como um sentido "mobilizado a serviço dos indivíduos e grupos dominantes". Nessa concepção de ideologia, podemos destacar a consideração da realidade constituída a partir de uma participação ativa dos indivíduos.

Por outro lado, Kress e van Leeuwen (2000 apud Almeida, 2008) discutem as teorias gramaticais verbais, que se configuram como uma organização metafuncional para análise das imagens. Além disso, essas teorias são fundamentadas nos princípios da gramática do linguista britânico Michael Halliday. Em síntese, de acordo com Almeida (2008), para análise dos objetos visuais, é preciso um determinado nível de letramento do observador, para que seja possível analisar e compreender as estruturas visuais.

\section{O método oralista}

Em relação ao filme de Michaels (1979), apresentado na introdução deste artigo, a reinserção do garoto Jonas no seio familiar é marcada por momentos de tensão. As cenas que mostram o retorno de Jonas para casa são exemplos disso. Além disso, os conflitos são constantes e não se restringiam à casa, mas ocorriam também em diversos espaços sociais, especialmente, no âmbito escolar. 
E o Seu Nome é Jonas: Recursos Visuais e Textuais/Verbais como Crítica ao Discurso Oralista na Educação de Surdos

Tatiane da Silva Carvalho Pereira • Gláucia Vieira Cândido, et al...

Jenny, ao notar que o filho não está progredindo na escola, conversa com a diretora. A educadora e administradora escolar é enfática ao defender os métodos orais como os mais adequados para as crianças surdas. Por isso, a escola não permitiria o uso de gestos entre os alunos. Notoriamente, esse posicionamento da representante escolar explicita sua crença na proposta oralista, a qual, em conformidade com Quadros (1997, p. 21), fundamenta-se na "recuperação" da pessoa surda, ou seja, do 'deficiente auditivo', termo técnico adotado, com ênfase na língua oral e em temos terapêuticos.

Embora sem conhecimento empírico e teórico do assunto, é nítido o incômodo da mãe de Jonas com a situação. Por outro lado, também é evidente o fato de Jenny não conseguir identificar o que está ocorrendo com seu filho. Afinal, mesmo fazendo uso de aparelho auditivo, o garoto não compreendia a fala e, consequentemente, não conseguia se expressar por meio dela.

Entre as várias questões levantadas pela temática do filme, há uma que, a nosso ver, é importante tratarmos aqui: a aversão de Jonas ao brinquedo de seu irmão Antônio. Trata-se de um boneco, uma réplica do personagem de revistas em quadrinhos, Homem Aranha, criação dos escritores Stan Lee e Steve Ditko, de 1962.

Em uma cena retratada no quarto das crianças, os dois irmãos estão sentados na cama, folheando uma revista com histórias em quadrinhos do Homem Aranha. Na sequência, Antônio oferece a Jonas o boneco para brincar. Após receber o brinquedo, o irmão mais velho desce da cama, anda em direção a um armário, abre uma gaveta, coloca o boneco dentro e, em seguida, fecha. Após a reclamação de Antônio, a mãe entra em cena, adverte Jonas e retira o Homem Aranha da gaveta, devolvendo-o ao filho caçula.

No cenário, caracterizado como um quarto de meninos, alguns detalhes visuais chamam a atenção do telespectador, como, 
E o Seu Nome é Jonas: Recursos Visuais e Textuais/Verbais como Crítica ao Discurso Oralista na Educação de Surdos

Tatiane da Silva Carvalho Pereira • Gláucia Vieira Cândido, et al...

por exemplo, a placa com palavra em Inglês Stop ("Pare!"), pendurada na porta do quarto, para a qual percebe-se um ângulo de destaque no momento em que Jonas "se livra" do Homem Aranha, colocando-o na gaveta do móvel. Apesar de haver outros quadros decorativos no quarto, percebemos a proeminência da placa no quadrante da cena, tal como reproduzimos na Imagem 1, abaixo:

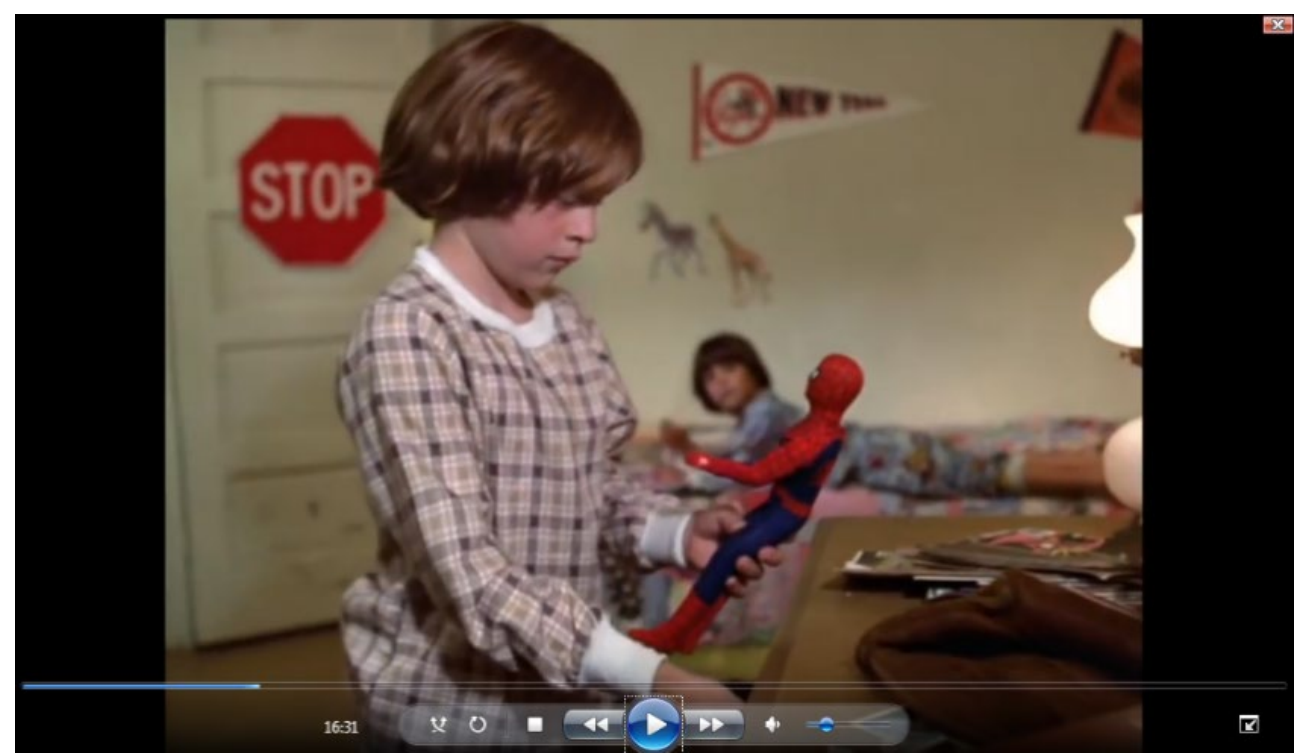

Imagem 1: Garoto Jonas, o irmão Antônio e o boneco do Homem Aranha. Fonte: Michaels 17:28' (1979).

Apoiados em Kress e van Leeuwen (2000 apud ALMEIDA, 2008, p. 11), destacamos que os recursos visuais: a) são representações; b) estabelecem relações interacionais; e c) "constituem relações de significado a partir de sua composição, de sua arquitetura". A partir disso, três estruturas de representações básicas são delineadas: representacional, composicional e interacional.

A estrutura representacional proposta por esses autores, conforme Almeida (2008), é obtida nas imagens por meio de participantes nelas representados, os quais podem ser pessoas, objetos ou lugares. Além disso, essa função é subdividida em estrutura narrativa, quando há a presença de vetores indicando que ações estão sendo realizadas, e em conceitual, quando existe uma taxo- 
E o Seu Nome é Jonas: Recursos Visuais e Textuais/Verbais como Crítica ao Discurso Oralista na Educação de Surdos

Tatiane da Silva Carvalho Pereira • Gláucia Vieira Cândido, et al...

nomia, uma classificação, em que os participantes representados são expostos como se estivessem subordinados a uma categoria superior. De outra forma, a primeira apresenta ações e eventos; a segunda, os participantes e suas particularidades.

Seguindo essa linha de raciocínio, podemos analisar a representação atribuída à atitude de Jonas na cena do "engavetamento do boneco do Homem Aranha", a partir da observação do enquadramento que é empreendido na referida cena como forma de representação conceitual assinalada pela pessoa do personagem, ou seja, por Jonas, e pelos objetos apresentados na mesma cena: o boneco do super herói e a placa de Stop ("Pare!") pendurada na parede.

A cena de Jonas com o brinquedo, na forma como está disposta, permite-nos identificar a função representacional dentro da categoria 'perspectiva' que, de acordo com Kress e van Leeuwen (apud ALMEIDA, 2008, p. 20), trata-se do ângulo ou ponto de vista em que os participantes representados são mostrados. No caso da Imagem 1, é interessante perceber que Jonas está em ângulo oblíquo. Dentro da função representacional, os autores definem que:

\begin{abstract}
à medida que os planos deixam de ser tomados de frente, provocados por um deslocamento, a perspectiva torna-se oblíqua, mostrando o participante de perfil, estabelecendo uma sensação de alheamento, deixando implícito que aquilo que vemos não pertence ao nosso mundo (KRESS E VAN LEEUWEN apud ALMEIDA, 2008, p. 21).
\end{abstract}

Assim, essa definição corrobora a representação da imagem apresentada, pois, a partir do comportamento empreendido por Jonas, podemos dizer que existe nela, de forma considerável, o empreendimento de elementos antagônicos ao discurso linguístico oralista, o qual é fortemente imposto ao garoto surdo. Disso, 
E o Seu Nome é Jonas: Recursos Visuais e Textuais/Verbais como Crítica ao Discurso Oralista na Educação de Surdos

Tatiane da Silva Carvalho Pereira • Gláucia Vieira Cândido, et al...

notamos que Jonas, em várias situações, expressa descontentamento com o objeto inanimado, o boneco do personagem de histórias em quadrinhos, o qual, por sua vez, pode ser tomado como a personificação de si mesmo no que diz respeito à impossibilidade de se expressar.

Em outra imagem, momento envolvendo o enquadramento da placa Stop, a cena apresenta o menino Jonas vivendo um impasse diante do uso ou não do aparelho auditivo, conforme a Imagem 2. Novamente, figura no cenário um móvel cuja gaveta recebe destaque, pois é usada pela criança, figurativamente, para "resolver" alguma de suas angústias, já que pode ser utilizada como depósito para "tirar de cena" um ser ou objeto que representa algum tipo de negação.

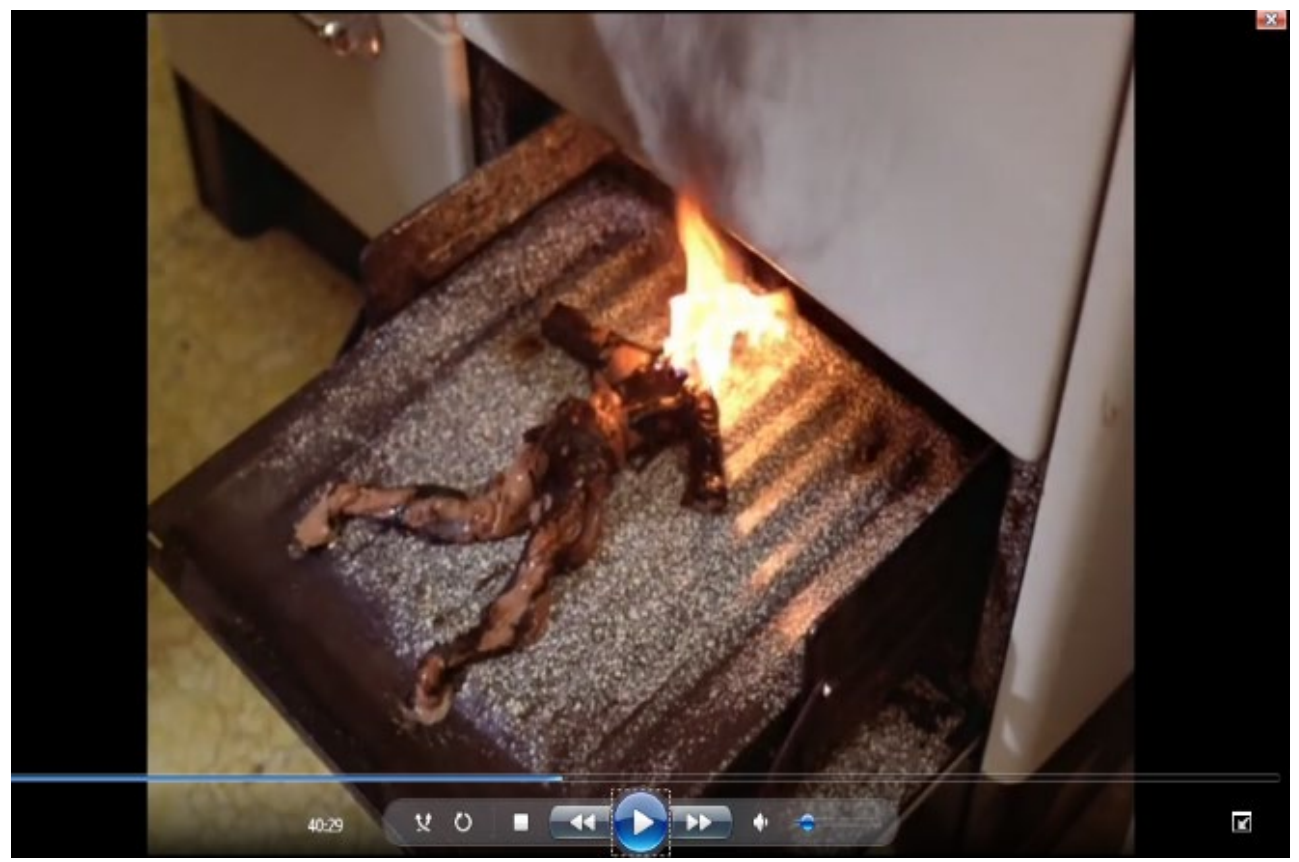

Imagem 2: Jonas e o Aparelho Auditivo.

Fonte: Michaels 01:03:07' (1979).

A imagem corresponde, na narrativa fílmica, ao momento em que o Jonas se entristece com a morte de seu avô, personagem por quem tinha imenso carinho e era, nas palavras da mãe do garoto, o melhor amigo de seu filho. A cena é a sequência de outra em 
E o Seu Nome é Jonas: Recursos Visuais e Textuais/Verbais como Crítica ao Discurso Oralista na Educação de Surdos

Tatiane da Silva Carvalho Pereira • Gláucia Vieira Cândido, et al...

que Jonas planeja sair escondido de casa para ir ao lugar onde seu avô trabalhava. Após se preparar para sair, o quadrante evidencia Jonas no instante em que ele se dirige ao móvel em que fica guardado seu aparelho auditivo. Disso, percebemos que Jonas tem intenção de pegar o aparelho (que se encontra guardado no móvel). Contudo, após um breve momento de reflexão, o menino hesita e acaba escondendo a aparelhagem embaixo do móvel, não mais na gaveta, onde poderia ser encontrado mais tarde por sua mãe.

A exemplo do que vimos na cena representada na Imagem 1, observamos ao fundo, mas com destaque, a placa com a palavra Stop colocada na porta do quarto das crianças. Disso, notamos que o destaque da placa expressa, figurativamente, o exato instante em que Jonas decide não mais fazer uso de seu aparelho auditivo. Na sequência, o menino sai de casa "livre" do acessório, que, na cultura oralista, seria fundamental para ela interagir socialmente.

Mais uma vez, identificamos a representação conceitual, segundo Kress e van Leeuwen (apud ALMEIDA, 2008, p. 23), dentro da categoria 'perspectiva', pois Jonas foi colocado no ângulo oblíquo, o favorece nossa análise. Além disso, o papel da função composicional pode ser identificado, o que, para os autores, trata-se da função de organizar/combinar os elementos visuais de uma imagem integrando os elementos representacionais e interativos em uma composição. Para os autores, os significados dos elementos de uma composição são explicados por meio de três sistemas inter-relacionados: valor de informação, saliência e estruturação.

Dada a análise, ressaltamos a definição da composição 'saliência', pois, nessa categoria, "os elementos são feitos para atrair a atenção do espectador em diferentes níveis: plano de fundo ou primeiro plano, tamanho, contrastes de tons e cores, diferenças de nitidez entre outros (KRESS E VAN LEEUWEN apud ALMEIDA, 2008, p. 23). 
E o Seu Nome é Jonas: Recursos Visuais e Textuais/Verbais como Crítica ao Discurso Oralista na Educação de Surdos

Tatiane da Silva Carvalho Pereira • Gláucia Vieira Cândido, et al...

Nesse momento, temos a impressão de que há um propósito empreendido para a desconstrução da relação de poder existente sobre o discurso da oralidade como único meio de aquisição da linguagem por pessoas surdas. Afinal, Jonas nega o uso do apareIho auditivo e, ao mesmo tempo, tem-se o destaque da imagem da placa Stop, o que projeta a categoria 'saliência', além de corroborar a tese de crítica à filosofia oralista, iniciada em finais do século XIX, e que, como já dito em seções anteriores deste texto, perdurou por quase cem anos como o único método permitido para educação e escolarização da pessoa surda.

Seguindo a análise, por meio das imagens que representam as cenas do filme em pauta, a crítica ao oralismo ganha força no evento em que o boneco do personagem Homem Aranha é flagrado por Jenny sendo incinerado no forno do fogão de sua cozinha. Trata-se da sequência das cenas em que Jonas subtrai, sem o conhecimento da família, o boneco de seu irmão e o esconde na parte inferior do forno do fogão.

Após uma das discussões com o esposo, por causa de sua dedicação à educação formal, em que o pai manifesta um discurso de descrédito em relação à competência do filho em relação aos processos de aprendizagem na escola ${ }^{4}$, a mãe de Jonas adentra a cozinha e sente o cheiro forte de algo sendo queimado. Ao abrir a porta do forno, Jenny depara-se com o boneco já desconfigurado em função de um estado de carbonização, conforme se vê na Imagem 3:

4 - Na tradução para o Português, o pai de Jonas, Danny, refere-se ao filho como "retardado mental", expressão de cunho pejorativo. Essa expressão era usada por várias outras pessoas, incluindo profissionais da saúde e até mesmo os da educação. Nesse tipo de enunciado, materializam-se os valores ideológicos de grupos sociais que contribuem para a formação da identidade desses grupos. A dramaturgia E o seu nome era Jonas (1979) expõe a identidade de vários grupos sociais, em sua maioria, com ideologia de preconceito e desconhecimento sobre as condições de pessoas com necessidades especiais em momentos de nossa história recente (provavelmente décadas de 70 ou 80). 0 início da película apresenta cenas de um hospital psiquiátrico, onde estão internadas várias crianças, incluindo o garoto surdo Jonas. Essas crianças, em sua maioria, apresentam o fenótipo da Síndrome de Down, cujas internações não se justificariam na atualidade, pois se sabe que deficiências cognitivas não são razões para internação de nenhuma pessoa na atualidade. Ao contrário, as dificuldades enfrentadas por crianças com necessidades especiais generalizadas podem ser minimizadas com o apoio da família e da comunidade geral, em especial, especialistas como os profissionais da saúde, como fisioterapeutas, fonoaudiólogos, além psicopedagogos, entre outros. 
E o Seu Nome é Jonas: Recursos Visuais e Textuais/Verbais como Crítica ao Discurso Oralista na Educação de Surdos

Tatiane da Silva Carvalho Pereira • Gláucia Vieira Cândido, et al...

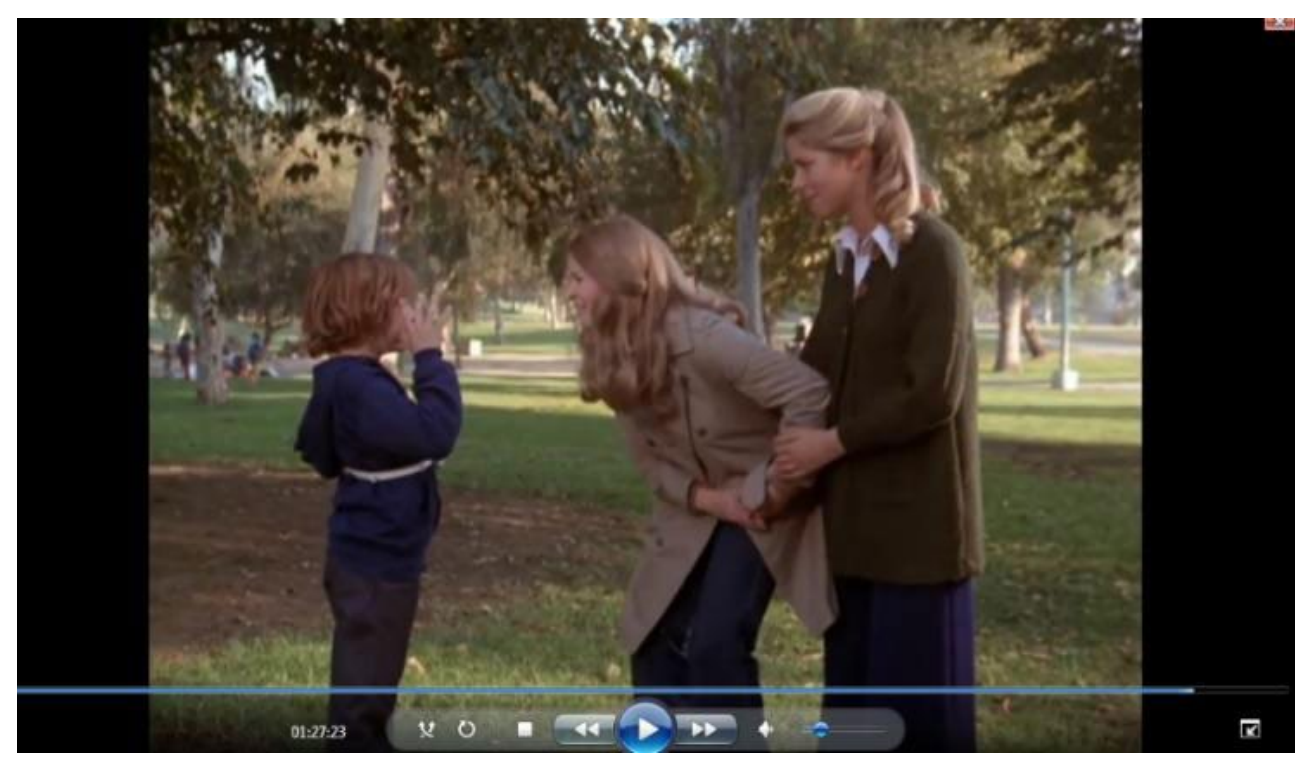

Imagem 3: O boneco do Homem Aranha em chamas no forno. Fonte: Michaels 41:21'(1979).

Essa cena carrega uma carga emocional significativa. A imagem, a partir da análise do contexto representado, haja vista que se trata de um filme produzido no final da década de 1970, fez-nos concluir que seu semantismo corresponde a uma conjuntura de sentimentos resinificados por parte da população surda sobre o uso da língua de sinais. Disso, salientamos que, por quase um centenário, o surdo foi privado de sinalizar, ou seja, impedido, de certa maneira, de se comunicar e interagir com a família e outros grupos sociais.

Pontuamos que, ao observarmos a imagem do boneco do Homem Aranha em avançado processo de incineração, apesar de o brinquedo estar muito queimado, na cena em foco, as chamas do fogo que o consumiu restringem-se apenas à cabeça. Em nossa percepção, isso configura certa intencionalidade, haja vista que, no quadrante, o que se tem são os olhos, a boca, os ouvidos e o cérebro, na totalidade de órgãos de sentido e de intelectualidade, sendo consumidos pelas últimas chamas.

Pautados nessas reflexões, conjecturamos que a pirólise ${ }^{5}$ do boneco do personagem Homem Aranha possibilita identificar, fi-

5 - Processo de decomposição térmica de material orgânico ou inorgânico em função de exposição a altas temperaturas, a exemplo do que ocorreu com o brinquedo ao ser colocado no forno em funcionamento. 
E o Seu Nome é Jonas: Recursos Visuais e Textuais/Verbais como Crítica ao Discurso Oralista na Educação de Surdos

Tatiane da Silva Carvalho Pereira • Gláucia Vieira Cândido, et al...

gurativamente, as barreiras linguísticas, sociais e culturais, enfrentadas por Jonas. Na Imagem 3, nessa perspectiva, a queima da parte superior do boneco pode ser compreendida da seguinte forma: a imagem dos olhos reitera que a língua de sinais é visual, mas há certos impedimentos para seu uso efetivo; a imagem dos ouvidos relaciona-se à perda auditiva de Jonas; a imagem da boca retoma a ideia de persistência das terapias da fala; e, por fim, a imagem do cérebro remete-nos ao fato de Jonas não conseguir exteriorizar seus pensamentos via linguagem oral, sendo tomado pelos outros como deficiente intelectual.

Nessa direção, apontamos também o fato de que o brinquedo, após sofrer a queimadura, é mostrado com as mãos aparentemente removidas, desmembradas. Frente a esse elemento figurativo, levantamos a hipótese de que um sentimento pode estar permeando o cotidiano de Jonas. Afinal, como a imagem objetiva mostrar, por não conseguir estabelecer a comunicação, o sujeito surdo pode não aprender a falar, bem como não conseguir se expressar e interagir com os outros.

Além disso, a frustração de Jonas é representada na narrativa fílmica no momento em que ele vê um carrinho de vendas de cachorro-quente, corre até onde está sua mãe para que ela possa ir com ele ao encontro do comerciante, mas, tanto a mãe quanto o filho, não conseguem sinalizar, ou seja, a comunicação fica prejudicada. Quando o garoto consegue ser entendido, após arrastá-la até o lugar onde o carrinho de cachorro-quente estava, o comerciante já havia saído de lá, desaparecendo nas ruas da cidade e deixando, em Jonas, a frustração por não conseguir fazer com que a mãe comprasse para si um cachorro-quente.

Assim, concluímos que Jonas, aparentemente, se reconhece de forma negativa no personagem Homem Aranha. Como já demostrado, a máscara desse personagem deixa evidente apenas 
E o Seu Nome é Jonas: Recursos Visuais e Textuais/Verbais como Crítica ao Discurso Oralista na Educação de Surdos

Tatiane da Silva Carvalho Pereira • Gláucia Vieira Cândido, et al...

seus olhos, sua a boca é escondida, o que, na visão de Jonas, pode significar que o boneco não consegue se expressar, ou seja, o Homem Aranha, assim como Jonas, estaria totalmente alheio à comunicação oral. Nesse sentido, apontamos consequências negativas da oralização na vida de Jonas a partir da completa aversão que ele demonstra sentir pela figura do Homem Aranha. Essa aversão é materializada, possivelmente, por sua experiência real no universo malsucedido da oralização.

Ainda no que tange à Imagem 3, identificamos que Jonas, diante da impotência de se comunicar, é obrigado a utilizar uma língua oral, cuja aquisição está sendo uma tarefa extremamente difícil e, por vezes, traumatizante, já que inclui castigos por parte dos educadores. Esses acontecimentos revelam, novamente, um contexto de extrema angústia e sofrimento retratados na narrativa fílmica por essa e outras cenas.

Ao personificar internamente o personagem Homem Aranha, ou seja, ao se reconhecer como um indivíduo que não tem boca e, por consequência, não oraliza/fala, Jonas toma a atitude de eliminá-lo de vez de sua vida. Nessa atitude do menino surdo, depreendemos uma representação do que Thompson (1995, p. 87) definiu como modo de operação da ideologia, sendo esta caracterizada pela "fragmentação".

Além disso, como estratégia de construção simbólica, o "expurgo do outro" se dá a partir da construção de um inimigo (no caso de Jonas, o personagem Homem Aranha, materializado pelo boneco de seu irmão mais novo), seja ele interno ou externo, o qual é retratado como mau, perigoso e ameaçador (ainda que seja exatamente o contrário, no caso do super-herói das histórias em quadrinhos, que costuma encantar tantas crianças no mundo inteiro desde a sua criação até os tempos hodiernos) e contra quem as pessoas são orientadas a resistir de modo coletivo ou até mesmo a expurgá-lo. 
E o Seu Nome é Jonas: Recursos Visuais e Textuais/Verbais como Crítica ao Discurso Oralista na Educação de Surdos

Tatiane da Silva Carvalho Pereira • Gláucia Vieira Cândido, et al...

Enfim, as colocações expostas enfatizam, a partir do filme de Michaels (1979), os momentos em que o oralismo e o ouvintismo prevaleceram na vida dos protagonistas. É notório, a nosso ver, como tais filosofias refletiram significativamente na vida do indivíduo surdo (representado por Jonas, por exemplo) por várias décadas. Não há dúvidas de que se tratou de uma repercussão negativa, visto que o fracasso de Jonas - seja ele escolar e, por consequência, social, cultural e linguístico - foi significativamente explorado na narrativa fílmica.

\section{A ressignificação da comunicação por meio da língua de sinais}

Como já vimos nas seções anteriores, Jonas, ao sair do hospital psiquiátrico, foi apresentado à fala, ou seja, à oralização como meio de comunicação. Contudo, o garoto não alcançou êxito no desenvolvimento da linguagem nesses moldes. Para além do atraso no desenvolvimento cognitivo, houve também imenso abalo na estrutura familiar, que resultou no abandono do lar por parte do pai de Jonas. Além disso, o ciúme do caçula da família, Antônio, em relação aos cuidados que seu irmão mais velho recebe; a morte do avô e melhor amigo de Jonas; os problemas financeiros; e a persistente angústia de Jenny com respeito ao método adotado pela escola para educação de seu filho surdo foram ressaltado ao longo do filme.

No avançar da narrativa fílmica, contudo, o enredo começa a tomar outro rumo a partir das cenas em que Jenny é mostrada aguardando, em uma sala de espera de uma clínica especializada, a finalização do atendimento terapêutico de Jonas. O foco é o momento em que a Sra. Corelli nota a presença de uma família surda que usava a língua de sinais para interagir entre si. A nar- 
E o Seu Nome é Jonas: Recursos Visuais e Textuais/Verbais como Crítica ao Discurso Oralista na Educação de Surdos

Tatiane da Silva Carvalho Pereira • Gláucia Vieira Cândido, et al...

rativa segue mostrando que, com a passagem do tempo, Jenny, motivada pela angústia que a afligia, resolve abordar o casal e seu filho, expondo-lhes sua curiosidade acerca do método usado para se comunicarem.

Notamos que, inicialmente, a comunicação/interação com a família surda foi dificultada pelo fato de Jenny não sinalizar. Com isso, foi necessário recorrer à escrita para estabelecer comunicação entre eles. Todavia, como a esposa oralizava (explicou a Jenny que havia ficado surda na infância), a mãe de Jonas conseguiu expor o seu desejo de conhecer mais sobre o mundo dos surdos. Diante disso, o casal a convida para ir a uma reunião da associação de surdos da qual faziam parte. Jenny prontamente aceita o convite e o estende a uma amiga que também tem um filho surdo.

Nas cenas seguintes, vemos as duas mulheres indo juntas a um evento semelhante, ou melhor, a uma confraternização. Nesse instante, elas foram gentilmente recepcionadas pelo casal de surdos. Nesse momento, elas foram apresentadas a outras pessoas, incluindo uma intérprete da língua de sinais, para ajudá-las a interagir com as pessoas surdas, além do simpático Woody, um rapaz surdo que, com gentileza, ensinou a elas vários sinais, ou seja, os elementos léxicos da língua de sinais (GOLDFELD, 2002, p. 25).

As imagens retratadas na película demonstram que Jenny e sua companheira de lutas, pois elas têm crianças surdas, apresentaram verdadeiro fascínio com tudo que viram e aprenderam. Além disso, após o evento na associação de surdos, Jenny decidiu conversar com a gestora da escola. Nessa conversa, a mãe de Jonas anunciou o desejo de que seu filho surdo e toda sua família aprendessem a língua de sinais.

Naturalmente, considerando a filosofia seguida pela instituição de ensino em relação a alunos surdos, a reação da diretora não foi nada encorajadora. De maneira ríspida, a diretora decla- 
E o Seu Nome é Jonas: Recursos Visuais e Textuais/Verbais como Crítica ao Discurso Oralista na Educação de Surdos

Tatiane da Silva Carvalho Pereira • Gláucia Vieira Cândido, et al...

rou não gostar de "perder uma criança para a surdez". A mãe de Jonas lembra ter ouvido da educadora que existiam crianças que falharam nesse processo e questionou se seu filho não seria um desses casos. Sem resposta, Jenny assegurou que não fora Jonas quem havia falhado, mas sim ela, a própria mãe, quando optara por fingir que a criança não era surda.

Em resposta à Jenny, apontamos o discurso adotado pela administradora escolar, impregnado da filosofia ouvintista: “Não há virtudes em ter um filho surdo; o mundo ainda é dos ouvintes!". Todavia, Jenny, então fortalecida por uma nova perspectiva ideológica, já saindo do ambiente, devolve: “Nós, que amamos Jonas, devemos ajudá-lo a viver na surdez". Em contrapartida e em tom mais autoritário e intimidador, a gestora ainda insiste: "Sra. Corelli, não permitirei que Jonas use os sinais em nossas aulas!". Jenny se volta para a diretora e lhe questiona se essa decisão se deve ao fato de a mulher pensar que o uso de sinais poderia ser contagioso; em resposta, a gestora retruca: "Quando eu era jovem, no início do magistério, as crianças que usavam os sinais, tinham as mãos amarradas. Não irei permitir os sinais". Indignada, Jenny se vira e deixa a sala.

A partir daí, dizemos que os sentidos do texto, como prática social de linguagem, não refletem apenas uma realidade específica, ou seja, de apenas um determinado grupo ou classe social. Por exemplo, o discurso da diretora vai ao encontro daqueles produzidos por uma parcela considerável de profissionais da área médica, para quem muitas vezes a surdez é uma deficiência.

Em contrapartida, os enunciados produzidos por Jenny são reproduzidos de acordo com as interações sociais que legitimam suas práticas e que corroboram seus sentidos, os quais são aceitos, de alguma forma, pela sociedade. Enquadram-se, nesse conjunto, aqueles para quem a surdez deve ser analisada pelo âmbito 
E o Seu Nome é Jonas: Recursos Visuais e Textuais/Verbais como Crítica ao Discurso Oralista na Educação de Surdos

Tatiane da Silva Carvalho Pereira • Gláucia Vieira Cândido, et al...

cultural e, assim sendo, não deve ser considerada uma deficiência (CHRISTMANN, 2015, p. 17). Os telespectadores do filme, a partir de suas experiências individuas e sociais como sujeitos de sua própria história, atribuirão sentido a tais enunciados construindo realidades a partir do texto, do discurso e do funcionamento da linguagem em sociedade.

A sequência das cenas mostra Jenny e os filhos socializando em um parque com os novos amigos: o jovem surdo Woody e a intérprete. O jovem passou a ensinar aos dois irmãos vários sinais que, a princípio, pareceram não estar sendo assimilados pela criança surda, pois esta se mostrava um pouco confusa. Contudo, ao entender que os sinais têm significados e referentes no mundo que o cerca, a comunicação foi sendo efetivada. Nessa direção, o "Eureca, eureca!" de Jonas se dá quando ele avista um carrinho de venda de cachorro-quente. Nesse momento, o garoto entende e toma posse dos novos conhecimentos e o uso deles passa a fazer sentido. A alegria de Jonas, do irmão e da mãe, na ocasião em que a criança surda compreende a finalidade da sinalização, é registrada na Imagem 4.

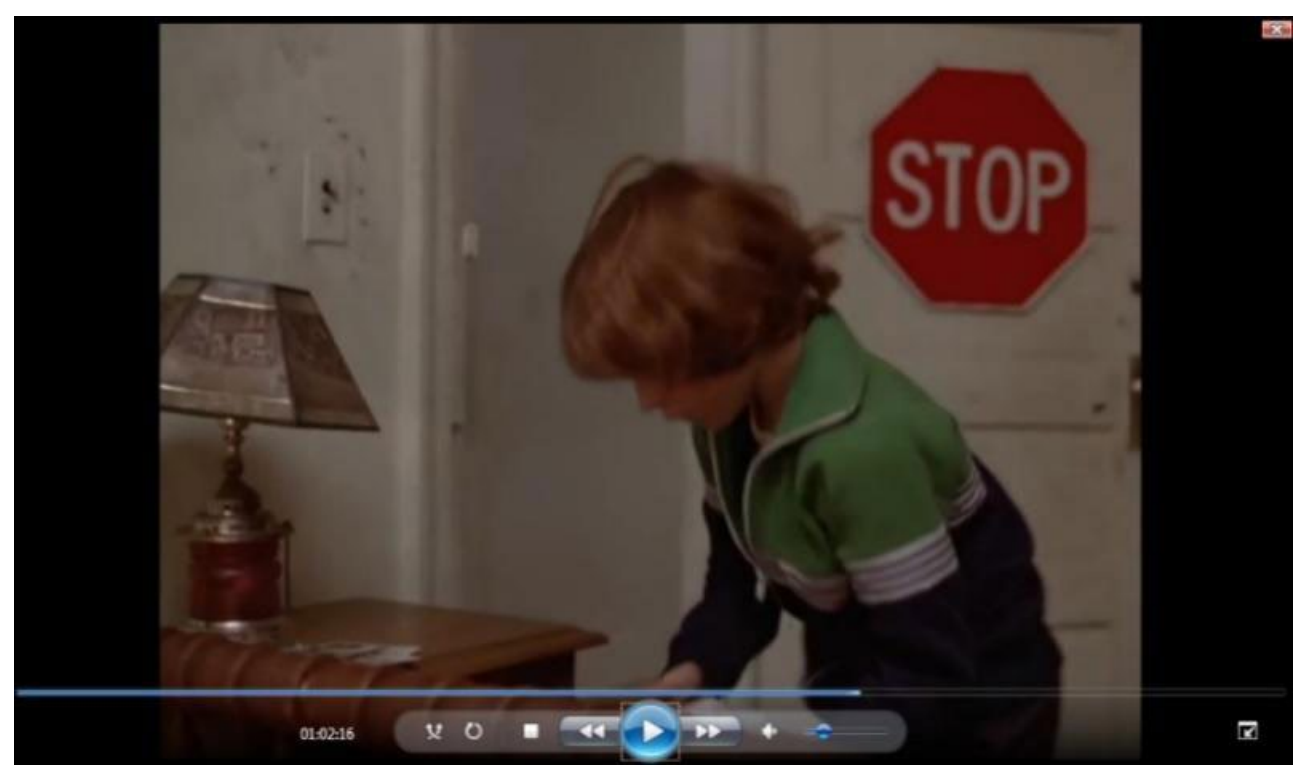

Imagem 4: Jonas sinalizando "mamãe" pela primeira vez. Fonte: Michaels 01:28:11'(1979). 
E o Seu Nome é Jonas: Recursos Visuais e Textuais/Verbais como Crítica ao Discurso Oralista na Educação de Surdos

Tatiane da Silva Carvalho Pereira • Gláucia Vieira Cândido, et al...

Essa imagem corresponde ao momento em que, após o contato com a língua de sinais, por meio dos ensinamentos de Woody, o garoto olho para sua mãe e se mostra interagir com a situação. Nesse instante, o Woody compreende que Jonas quer saber como usar a palavra "mamãe" na língua de sinais. O professor surdo indica o sinal específico a Jonas que, em seguida, corre até a sua mãe para reproduzir o sinal apreendido. Podemos dizer que a felicidade de Jenny pelo uso do sinal é comparada àquela sentida pelas mães quando seus filhos não surdos produzem, na forma oral, a palavra "mamãe". Sentimentos, como orgulho, surpresa, alegria, frente à aquisição da língua falada por suas crianças, se misturam.

\section{Considerações finais}

A história de Jonas Corelli, uma criança surda que foi obrigada 28 a passar três anos internada em um hospital psiquiátrico por causa de um diagnóstico de deficiência mental, postou-se para nós, interessados no universo da surdez, como uma instigante narrativa a ser estudada. Isso porque o caso narrado apresenta alguns elementos cujo objetivo parece ser o de implementar uma crítica à filosofia oralista, baseada nos pressupostos da legitimação da língua de sinais como meio de comunicação e expressão.

Ao propormos, neste artigo, uma breve análise dos recursos visuais e textuais/verbais que envolvem a narrativa fílmica de Michaels (1979), importou-nos principalmente destacar as relações de poder existentes nessa produção audiovisual. Isso porque algumas das diversas formas de discurso presentes na narrativa fílmica, levam-nos a identificar uma tentativa de construir uma representação contrária à estabelecida inicialmente: a filosofia bilinguista em detrimento da oralista.

Acreditamos que nossa proposta poderá, então, contribuir para ampliar os conhecimentos obtidos por meio da literatura es- 
E o Seu Nome é Jonas: Recursos Visuais e Textuais/Verbais como Crítica ao Discurso Oralista na Educação de Surdos

Tatiane da Silva Carvalho Pereira • Gláucia Vieira Cândido, et al...

pecífica acerca dos difíceis caminhos percorridos pelas pessoas surdas ao longo de nossa História. Afinal, esse filme reforça a tese de que o oralismo, filosofia que defende a integração da criança surda na comunidade ouvinte, por meio do desenvolvimento da língua oral, impôs sofrimento aos surdos por quase um século, visto ter sido utilizada institucionalmente como único método para o ensino de pessoas surdas durante esse período.

Como mostram os estudos de Goldfeld (2002) e outros, a proposta ouvintista trouxe como consequências uma série de defasagens no processo de aprendizado das pessoas surdas. A obrigatoriedade de comunicação por meio da oralidade e a proibição do uso das línguas de sinais, tal como representados pela diretora da escola para onde Jonas foi levado ao sair do hospital psiquiátrico, proporcionaram um significativo atraso no desenvolvimento dos indivíduos surdos.

29

Afinal, em consonância com Christmann (2015), o que limita o acesso do surdo às informações é a falta de comunicação, o que pode ser resolvido com a aprendizagem e uso da língua de sinais. De modo geral, por meio do tema abordado na narrativa fílmica, percebemos a intencionalidade de representação da cultura surda (discurso), em que se apresenta a possibilidade de comunicação propositadamente bem-sucedida. A nosso ver, há de se reconhecer que esta possibilidade faz parte de um contexto de ressignificação da língua de sinais amplamente defendido a partir da década de 1970, quando começaram a surgir as pesquisas referentes à estrutura das línguas de sinais e, consequentemente, a identificação e reconhecimento da cultura surda.

Por isso, assim como foi mostrado no filme, faz-se mister proporcionar à pessoa com surdez o uso incondicional de sua língua natural. Nesse sentido, as políticas públicas, em especial, as voltadas para a educação dos surdos, devem ocorrer de acordo com o 
E o Seu Nome é Jonas: Recursos Visuais e Textuais/Verbais como Crítica ao Discurso Oralista na Educação de Surdos

Tatiane da Silva Carvalho Pereira • Gláucia Vieira Cândido, et al...

contexto em que eles estão inseridos. Assim, preservar-se-á sua identidade cultural, o que Ihes permitirá acesso ao conhecimento geral, linguístico, social, político, econômico e educacional.

Não há dúvidas de que muito ainda precisa ser feito. Por ora, esperamos que este estudo possa implementar a necessária crítica à filosofia oralista baseada nos pressupostos da legitimação da língua de sinais como meio de comunicação e expressão. Sendo assim, surge um posicionamento passível de fortalecimento rumo ao direito linguístico e cultural conquistado, que seria a liberdade diante do uso das línguas de sinais.

\section{Referências}

Almeida, Danielle Lins de. Perspectiva em Análise Visual: do fotojornalISMO AO BLOG. JoÃo PESSOA: EdITORA dA UFPB, 2008.

30

CAMPOS, Mariana de Lima ISAac LeandRo. EduCaÇÃo InClusiva PARA SURdos e as políticas vigentes. In: LACERDA, Cristina Broglia Feitosa de; SANTOS, Lara Ferreira dos (Org). Tenho um aluno surdo, e agora? São Carlos: EDUFSCAR, 2014.

CHRISTMANN, Karina Elis. O PRocesso de AQUISIÇÃo da LiNGUAGEM de CRIANÇAS SURDAS COM IMPLANTE COCLEAR EM DOIS DIFERENTES CONTEXTOS: APLICAÇÃO DO MÉTODO EXTENSÃO MÉDIA DO ENUNCIADO (EME) E APRESENTAÇÃO DE ESTUDOS DOS ESTÁGIOS DE AQUISIÇÃO COM DADOS EM LíNGUA DE SINAIS. 2015. 89 F. Dissertação (Mestrado em Linguística) - Universidade Federal de Santa Catarina, Florianópolis, 2015.

FAirClough, Norman. Teoria Docial e Discurso. In: FAIRCLOUGH, Norman. Discurso e mudança social. Brasília: Editora da Universidade de BrasíliA, 2001.

GeSSER, Audrei. O Ouvinte e a Surdez: sobre ensinar e Aprender a Libras. São Paulo: Parábola Editorial, 2012. 
E o Seu Nome é Jonas: Recursos Visuais e Textuais/Verbais como Crítica ao Discurso Oralista na Educação de Surdos

Tatiane da Silva Carvalho Pereira • Gláucia Vieira Cândido, et al...

GOLDFELD, Márcia. A Criança Surda: linguagem e cognição numa perspectiva sociointeracionista. São Paulo: Plexus Editora, 2002.

haRRison, Kathryn Marie Pacheco. Libras: apresentado a língua e suas CARACTERÍSTICAS. IN: LACERDA, C.B.F. DE; SANTOS, L.F.S. DOS; CAETANO, J. $F(O r g)$. Tenho UM ALUNO SURdo, E AgORA? InTROdUÇão À Libras E EdUCAÇÃo de surdos. São Carlos: EdUFSCAR, 2014.

honora, Márcia. Inclusão Educacional de Alunos com Surdez: conCepção e Alfabetização: ensino fundamental, $1^{\circ}$ Ciclo. São Paulo: Cortez, 2014. kOjima, Catarina Kiguti. Segala, Suel Ramalho. Libras: Língua BraSileira de Sinais: a imagem do pensamento. São Paulo: Escala, 2008.

MiChAELS, Richard. E seu nome É Jonas. DiReÇão: Produção dos autores. EUA: Orion Pictures Corporation, 1979, 94 min.

QUAdROS, Ronice Müller de. Educação de Surdos: A aquisição da linguagem. Porto Alegre: Artmed, 1997.

PEReira, Tatiane da Silva Carvalho. O processo de aquisição da Língua Brasileira de SinaIS Por fiLhos SURdos de paIS OUVINTES: OS DESAFIOS E AS POSSIBILIDADES NOS CONTEXTOS FAMILIAR E ESCOLAR. 2020. 139F. DISSERTAÇÃO (Mestrado em Educação, Linguagem e Tecnologias) - Universidade Estadual de Golás, AnÁPolis-GO, 2020.

SilVA, Georgia Clarice da. A educação escolar de surdos na perspectiVA bilíngue de uma escola especial. 2015. 97F. Dissertação (Mestrado em Educação, Linguagem e Tecnologias) Universidade Estadual de Goiás, AnÁPolis-GO, 2015.

SilVA, Giselli Mara da. Perfis linguísticos de surdos bilíngues do par Libras-português. 2018217 f. TeSe (Doutorado EM Estudos Linguísticos) - Universidade Federal de Minas Gerais, Belo Horizonte, 2018.

SilVA, Jaqueline Ahnert Siqueira da. A educação da Criança surda com imPLANTE COCLEAR: REFLEXÕES SOBRE A FAMíliA, A CLÍNICA E A ESCOLA. 2013. 204f. 
E o Seu Nome é Jonas: Recursos Visuais e Textuais/Verbais como Crítica ao Discurso Oralista na Educação de Surdos

Tatiane da Silva Carvalho Pereira • Gláucia Vieira Cândido, et al...

DissertaçÃo (Mestrado em Educação) - Instituição de Ensino, Universidade Federal do Espírito Santo, Vitória, 2013.

thompson, Jhon Brookshire. Ideologia e Cultura Moderna: Teoria social críttca na era de comunicação de massa. Petrópolis - RJ: Vozes, 1995.

32

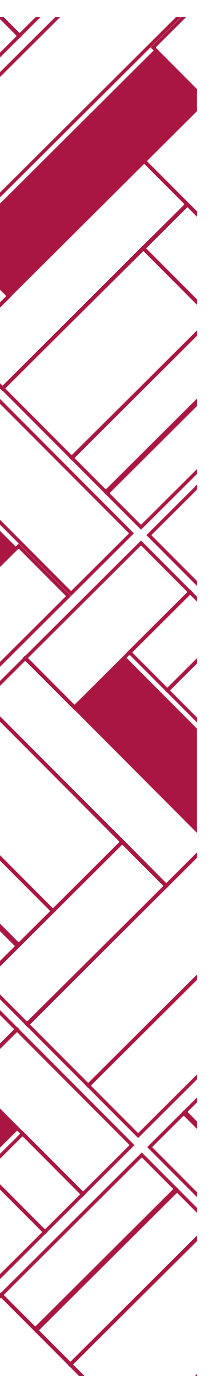

